\title{
Multi-criteria analysis of professional education on supply chain management
}

\author{
Claudemir Leif Tramarico** (D), Birsen Karpak ${ }^{\mathrm{b}}$ (D), Valerio Antonio Pamplona Salomon ${ }^{\mathrm{a}}$ (D), \\ Camila Aparecida Maciel da Silveira ${ }^{a}$ (D), Fernando Augusto Silva Marins ${ }^{a}$ \\ aUniversidade Estadual Paulista, Guaratinguetá, SP, Brasil

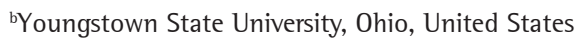 \\ *claudemir.leif@terra.com.br
}

\begin{abstract}
Paper aims: This paper presents an analysis of professional education programs on Supply Chain Management (SCM). The purpose of this study is to analyze six professional education programs offered by the leading SCM associations, including Advanced Certified Professional Forecaster, Certified Production and Inventory Management, Certified Professional in Supply Management, and Supply Chain Professional. The analysis of professional education programs shall consider relevant criteria. There are multiple relevant criteria; some are tangible, and some others are intangible.
\end{abstract}

Originality: In 2007 Prof. Lummus researched professional education influence to SCM practices. This work is an extension of Prof. Lummus research, updating it, including more professional education programs and analyzing with AHP.

Research method: This paper applied the Analytic Hierarchy Process (AHP), a method for multi-criteria analysis, considering individual benefits and organizational benefits as the two main criteria, and professional education programs as alternatives.

Main findings: The two major contributions of this paper are: first, it presents individual benefits and organizational benefits that must be met by professional education programs; second, it evaluates the programs from multiple perspectives.

Implications for theory and practice: The approach proposed evaluates both tangible and intangible benefits of the programs.

Keywords

Analytic hierarchy process. Professional education. Supply chain management.

How to cite this article: Tramarico, C. L., Karpak, B., Salomon, V. A. P., Silveira, C. A. M., \&t Marins, F. A. S. (2019). Multi-criteria analysis of professional education on supply chain management. Production, 29 , e20180087. https://doi.org/10.1590/0103-6513.20180087

Received: Dec. 2, 2018; Accepted: July 17, 2019.

\section{Introduction}

The purpose of this paper is to identify the topics of professional education on Supply Chain Management (SCM) that, in practice, are valued by the organizations attempting to align their strategies and capabilities with their customer needs. The quality of education is important for SCM, as for any other field of knowledge. There are strategic guidelines for optimizing education and learning in SCM that contribute to sustaining the organization's competitive advantage (Gibson et al., 2016).

The delivery of SCM education should include appropriate instructional methods to enable learners to achieve those competencies required by industry to compete globally (Hohenstein et al., 2014) and meet the demand for qualified professionals, especially by firms that are integrated into global value chains (Cottrill, 2010).

The first professional education program in SCM was developed by APICS (The Association for Supply Chain Management, formerly, American Production and Inventory Control Society). Eleven years ago, Lummus (2007) found that APICS influence and contribution advanced and improved SCM practices. APICS has fought hard 
to increase the visibility and recognition of SCM as a professional field through Certified in Production and Inventory Management (CPIM) program.

Continuous improvement in both the quality of the education and the learners experience led SCM institutions such as the Council of Supply Chain Management Professionals (CSCMP) and Institute for Supply Management (ISM) to conduct regular surveys to identify skills and knowledge needed to perform successfully (Lutz \&t Birou, 2013). An analysis of different professional education programs can help companies to identify the best education programs that can influence the capabilities of the firm. Learning and training are relevant topics to achieve the companies benefits (Scavarda et al., 2017).

This work is an extension of Prof. Lummus's research. It contributes to the literature by examining professional education programs from multiple perspectives including tangible and intangible benefits that are offered by leading SCM associations such as APICS, CSCMP, ISM and others.

An analysis of professional education has to consider multiple relevant and often conflicting criteria. Multi-Criteria Decision-Making (MCDM) is the study of conflicting criteria in decision making (International Society on MCDM, 2018). Several methods of MCDM have been developed in the last decades, to support decision-making in both public policies and private companies (lshizaka \& Nemery, 2013). The Analytic Hierarchy Process (AHP) is a leading MCDM method; there have been many papers published in a variety international journals about the theory and application of this methodology (Tramarico et al., 2015; Wallenius et al., 2008). Our main objective in this paper is to analyze professional education on SCM, from multiple perspectives. The AHP seems to be the most appropriate methodology for this analysis since some of these multiple criteria are qualitative and some are quantitative.

This paper is organized as follows: Section Literature Review is focused on AHP applications on SCM, professional SCM and SCM associations' concepts, and research outlined using bibliometric studies. Section Methodology presents AHP steps. Section Application presents the multi-criteria analysis of professional education on SCM. This paper ends with Section Discussion and Conclusions followed by Acknowledgements and the References.

\section{Literature review}

This Section is organized into three different subsections. The first subsection provides an overview of AHP applications in SCM. We further extend the discussion with professional SCM in existing literature. Finally, the third subsection explores SCM associations.

\subsection{Analytic hierarchy process and supply chain management}

AHP applications in SCM field has been spreading over the last decades. Subramanian \& Ramanathan (2012) developed a review of published literature from 1990 to 2009 and covered relevant papers from refereed journals and revealed a significant number of AHP applications in SCM. Ho \&t Ma (2018) reviewed the literature on AHP and SCM. Their review highlighting includes as agility, risk management and performance.

The literature review presented here considers the main publications on SCM, highlighting topics as: customer focus, operations strategy, performance evaluation, production and distribution planning, from 2010 to first quarter, 2018.

Customer focus is known as act to deliver customer value while achieving profitable business results. Lau et al. (2016) developed a hybrid multi-criteria decision model for supporting customer-focused profitability analysis based on relationship, communication, customer factors, conflict, and commitment criteria using combination of activity-based costing ( $A B C$ ), fuzzy analytic hierarchy process (FAHP), and technique for order preference by similarity to ideal solution (TOPSIS) methods.

Strategy is an organization's action plan to achieve the mission. Operations strategy implements corporate strategy and helps to build a customer-driven firm. Ibrahim (2010) presented a structured methodology to develop an operations strategy for the IT service sector based on service and customer focus criteria using AHP.

Performance evaluation is used to assess how well an organization is achieving its desired objectives. Jakhar (2015) proposed a performance evaluation and a flow allocation decision model for a sustainable supply chain of an apparel industry based on sustainable supplier partnership, sustainable production, sustainable delivery and logistic performance criteria using AHP. Dey \& Cheffi (2013) develop framework for green supply chain performance measurement based on environmental planning, environmental auditing, management commitment, environmental performance, economic performance and operational performance criteria using AHP. 
Production planning is the approach taken in setting the overall manufacturing output to meet customer demand and distribution planning is the planning activities associated to transportation, warehousing, inventory levels, materials handling and order management (Pittman \& Atwater, 2016). Varthanan et al. (2012) developed of simulation AHP and Discrete Particle Swarm Optimization (DPSO) algorithm for generating multi-criteria production-distribution plan based on total cost minimization, overtime, outsourced production costs, backorder, hiring/laying-off, and trip-wise distribution costs criteria.

This section presented a comprehensive list of publications on AHP applications in SCM. This is a fertile research field with wide range of opportunities. Though AHP has been applied in a variety of areas our literature search indicated that it has not yet been implemented in evaluating professional education on SCM.

\subsection{Bibliometric research on professional supply chain management}

Bibliometric helps to analyze data logically, and to reveal patterns and conclusions that may not be immediately obvious. The research includes an overview of publications which show a close relationship to the study. In scientific papers, generally considered key characteristics are a significant contributor to current knowledge and expansion of the scientific frontier (Ricker, 2017).

We used the Web of Science Core Collection database for the period 2001 to first quarter, 2018 to retrieve the relevant literature in a systematic manner. We searched for all publications whose title matches "supply chain management", and "professional". We only considered publications in English. The results are 54 publications with 677 references cited in main categories of Web of Science: Business, Education, Educational Research, Management Science, and Operations Research. Table 1 presents a summary of the results.

Other databases, such as Google Scholar or Scopus could be included to enlarge the bibliometric study. However, only the Web of Science was enabled to perform a citation network analysis with CitNetExplorer (Van Eck \& Waltman, 2014). The h-index presented in Table 1 is based on publications ranked in descending order by their number of citations. Therefore, an h-index equals to 13 means that there are 13 items with 13 citations, or more (Hirsch, 2005).

Table 1. Results of bibliometric research.

\begin{tabular}{lc}
\hline \multicolumn{1}{c}{ ltem } & Value \\
\hline Number of articles & 54 \\
Number of cited references & 677 \\
Average of citation & 13 \\
$\mathrm{~h}$-index & 13 \\
\hline
\end{tabular}

The main sources identified in the research were: Business Process Management Journal, Decision Sciences, Interfaces, International Journal of Logistics Management, International Journal of Operations \& Production Management, International Journal of Physical Distribution Logistics Management, Journal of Business Logistics, Journal of Operations Management, and Supply Chain Management: An International Journal.

In Figure 1, publications including the words "SCM" and "professional" topic began in 2001 with one publication, in 2016 it reached 8 publications, the highest result of the period. In the last 5 years, there have been an average of 4 publications per year.

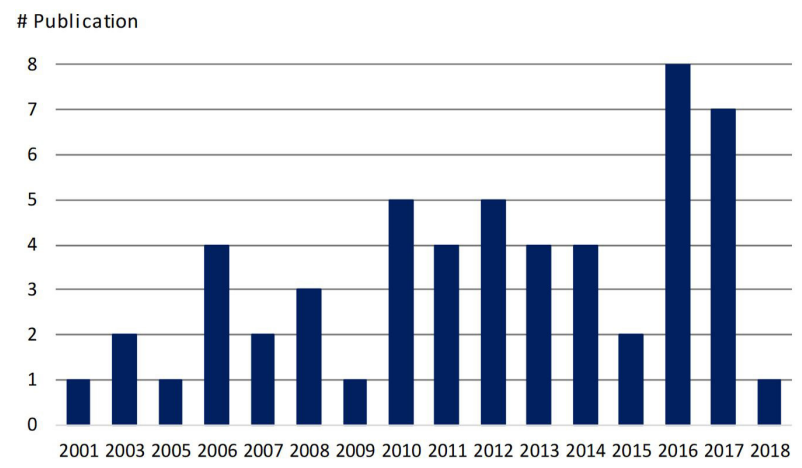

Figure 1. Publications on professional SCM (Web of Science, 2018). Notes: the number of publication (\# Publication) of the period is presented from 2001 to 2018. 
The number of citations (Figure 2) has increased significantly in recent years, from one citation in 2003 to 154 in 2016.

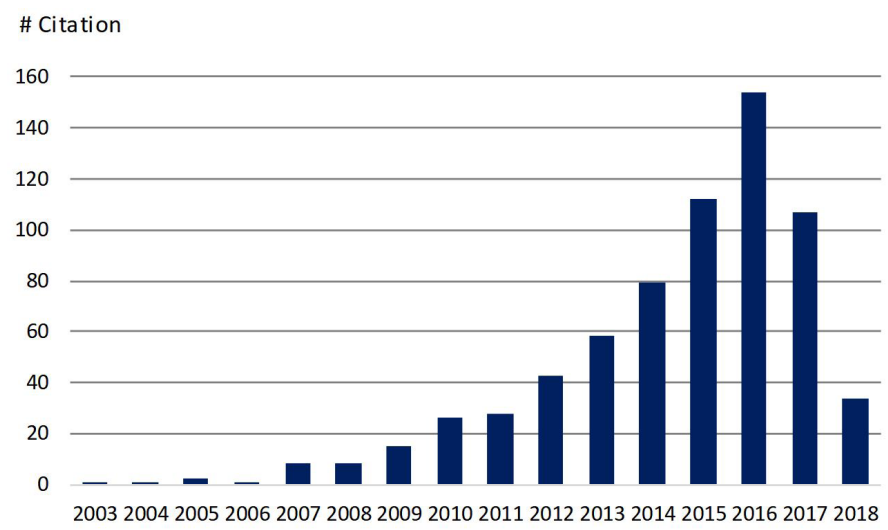

Figure 2. Citations on professional SCM (Web of Science, 2018). Notes: The number of citation (\# Citation) of each period is presented from 2003 to 2018.

At this stage, we applied a software for analyzing and visualizing citation networks. The tool is CitNetExplorer which is an abbreviation of "Citation Network Explorer", version 1.0, developed by the Centre for Science and Technology Studies (2018) of the University of Leiden, Netherlands. CitNetExplorer is used to study of the evolution of literature in each field of research and offers (Van Eck \& Waltman, 2014):

The citation network modeling was performed with CitNetExplorer. The input was 54 papers in the main categories of the Web of Science. After processing in the software, the citation network was generated from the relevance. Figure 3 presents the citation network, in which each circle represents a publication and carries the surname of the first author. It should be noted that one publication mentioning another is always located below the one it mentions (Van Eck \& Waltman, 2014). In Figure 3 the citation network was created from 27 publications, the location of a publication in the vertical dimension is determined by the year in which the publication appeared.

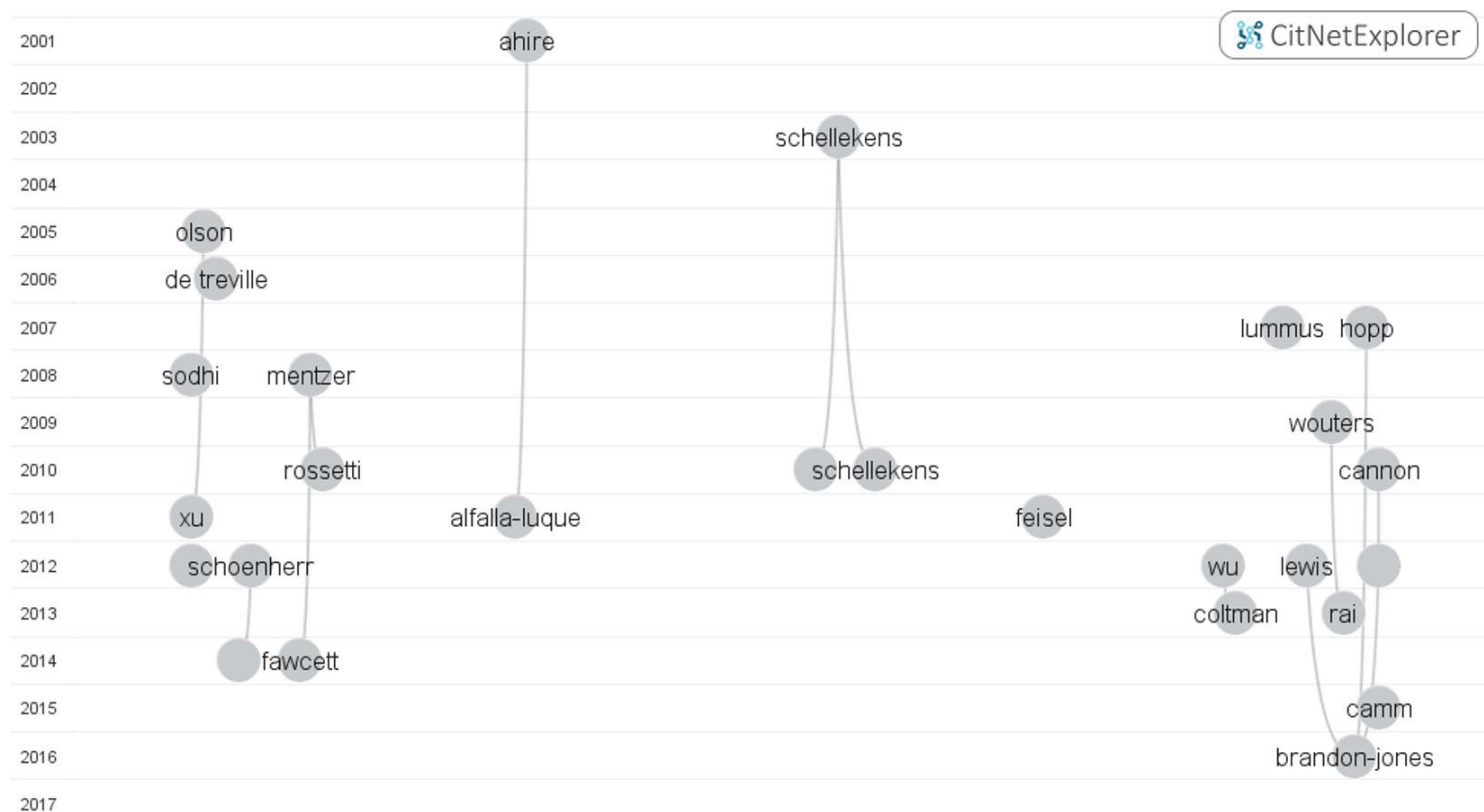

Figure 3. Citation network on professional SCM (Centre for Science and Technology Studies, 2018). 
In the citation network (Figure 3), Ahire (2001) is a predecessor (i.e., predecessors are publications cited by the selected publications). Ahire (2001) demonstrated business education relevance since business schools were making structural and curricular changes to improve the quality of instruction in SCM. Alfalla-Luque et al. (2011) proposed to improve instruction in SCM by taking the learner as a reference. Three educational environments, i.e., computer-assisted learning, face to face seminar and traditional distance teaching were analyzed. Schellekens et al. (2003) evaluated the flexibility in higher professional education in SCM. Schellekens et al. (2010a) design principles from SCM and instructional design were applied to create a flexible approach in educational programs. Schellekens et al. (2010b) contributed to SCM by designing a flexible educational model through discrete event simulation. Olson (2005) obtained quality ratings and rankings of 39 journals in operations management and related disciplines through surveys of faculty members at top-25 US business schools. De Treville and Van Ackere (2006) presented methods for reducing lead times required to each management learners using simulation. Sodhi et al. (2008) analyzed core operations management courses using input from MBA graduates, their analysis indicated that the supply usually matches demand; however, there may be an undersupply of practice- or process-oriented topics.

Lummus (2007) detailed the APICS CPIM and concluded that certification continues to find a target audience through new employees. Hopp et al. (2007) introduced discretion in task completion and added a fourth variability buffer, quality, to the well-known buffers of capacity, inventory and time. Mentzer et al. (2008) provided a SCM framework and its relationship to logistics, marketing, production, and operations management. Rossetti \& Dooley (2010) developed cluster analysis on similarity of SCM job descriptions and based on an industry view of a SCM professional. Fawcett \& Rutner (2014) identified important changes in logistics and SCM education based on academics and practitioner's perceptions of professional organizations, universities, and publications.

Wouters (2009) developed an approach to performance measures including how to convince employees to increase their commitment for performance improvement. Xu et al. (2011) evaluated journal quality on operations research and management science using correlations analysis. Rai \& Hornyak (2013) demonstrated the impact of supplier selection. Schoenherr \& Swink (2012) contributed to theory of integration (i.e. a confirmation of the significant benefits that firms can realize by being strategically interconnected and aligned with their supply chain partners). Schoenherr et al. (2014a) offered evidence to support the performance of the relationship between strategic environmental sourcing and both product development and product quality performance. Cannon et al. (2010) investigated the benefits of buyer-supplier relationships using a long-term orientation. Feisel et al. (2011) evaluated the importance of the human aspect in the purchasing and supply management function using survey. Lewis \& Brown (2012) detailed in a case study the operational and operations management characteristics of a professional service. Wu et al. (2012) examined the differences in operational practices and operational capabilities using a survey. Camm et al. (2014) conducted a survey of academically affiliated members of The lnstitute for Operations Research and the Management Sciences to better understand the extent of the usage of Interfaces, a premier journal of the practice of operations research and management science. Stouthuysen et al. (2012) evaluated supplier performance in professional services using a survey. Brandon-Jones et al. (2016) examined the characteristics and managerial challenges of professional services using a survey. Kotzab et al. (2018) identified specific qualifications and competences required within the field of logistics and SCM from the perspective of lifelong learning and hierarchical level.

The details about the topics and methods of the literature reviewed is presented in Table 2. Professional education was identified as the main topic in the citation network, the other topics identified were business education, capability, SCM education, operations research and management science, performance measurement and sourcing. The literature review presented reveals that professional education on SCM is emerging and has wide opportunity for exploration. One of the opportunities is evaluating professional education from multiple perspectives which is presented in this study. To the best knowledge of the authors this evaluation has not been assessed, yet, from multiple perspectives though it is a multiple criteria problem.

\subsection{Supply chain management association}

The SCM academic discipline has matured rapidly to keep up the growth of professional practice (Maloni \& Carter, 2018). SCM scholars have a much better understanding of processes from other disciplinary theories such as the resource-based view from management (Swanson et al., 2017), supply chain design (Fawcett et al., 2018) and interorganizational relationships (Krainer et al., 2018).

Roles of an SCM association include sharing knowledge with professionals working in SCM or a related field through essential educational programs that enhance knowledge and skills which combined with work experience to create the competencies required for individuals (Association for Supply Chain Management, 2018). In addition, SCM 


\begin{tabular}{|c|c|c|}
\hline Reference & Method & Topic \\
\hline Ahire (2001) & Case study & Professional education \\
\hline Alfalla-Luque et al. (2011) & Case study & Education \\
\hline Brandon-Jones et al. (2016) & Survey & Professional service \\
\hline Camm et al. (2014) & Survey & Operations research and management science \\
\hline Cannon et al. (2010) & Survey & Sourcing \\
\hline Coltman \& Devinney (2013) & Survey & Capability \\
\hline Fawcett \& Rutner (2014) & Survey & SCM education \\
\hline Feisel et al. (2011) & Case study & Sourcing \\
\hline Gibson et al. (2016) & Case study & SCM education \\
\hline Hopp et al. (2007) & Optimization & Operations Systems \\
\hline Kotzab et al. (2018) & Review of the literature & SCM and logistics competences \\
\hline Lewis \& Brown (2012) & Case study & Service operations \\
\hline Lummus (2007) & Case study & Professional education \\
\hline Lutz \& Birou (2013) & Survey & SCM education \\
\hline Mentzer et al. (2008) & Theoretical-conceptual & $\mathrm{SCM}$ \\
\hline Olson (2005) & Survey & Professional education \\
\hline Rai \& Hornyak (2013) & Correlations analysis & Sourcing \\
\hline Rossetti \& Dooley (2010) & Cluster analysis & SCM jobs \\
\hline Schellekens et al. (2003) & Survey & Professional education \\
\hline Schellekens et al. (2010a) & Simulation & Professional education \\
\hline Schellekens et al. (2010b) & Discrete event simulation & Professional education \\
\hline Schoenherr \& Swink (2012) & Survey & SCM strategy \\
\hline Schoenherr et al. (2014a) & Survey & Sourcing \\
\hline Sodhi et al. (2008) & Survey & Business education \\
\hline Stouthuysen et al. (2012) & Survey & Sourcing \\
\hline De Treville \& Van Ackere (2006) & Simulation & Professional education \\
\hline Wouters (2009) & Case study & Performance measurement \\
\hline Wu et al. (2012) & Survey & Capability \\
\hline Xu et al. (2011) & Correlations analysis & Operations research and management science \\
\hline
\end{tabular}

association roles help to develop industry-standard training and educational resources which enable professionals to gain the edge needed in todays' increasing competitive SCM professional environment and contribute to expanding capabilities across organizations.

The research presented in this paper has addressed six SCM associations with their main professional education program: APICS, CSCMP, ELA, IBF, ISCEA, and ISM. SCM associations are dedicated to developing and providing the body of knowledge in SCM and providing professional education programs that elevate excellence. Table 3 lists professional education program offered by leading SCM associations, in alphabetical order.

Table 3. Professional education program offered by leading SCM associations.

\begin{tabular}{lc}
\hline \multicolumn{1}{c}{ Professional education program } & SCM association \\
\hline ACPF (Advanced Certified Professional Forecaster) & IBF \\
CPIM (Certified Production and Inventory Management) & APICS \\
CPSM (Certified Professional in Supply Management) & ISM \\
CSCM (Certified Supply Chain Manager) & ISCEA \\
ECL (European Certified Logistician) & ELA \\
SC PRO (Supply Chain Professional) & CSCMP \\
\hline
\end{tabular}

SCM associations perform an important role in knowledge sharing and contribute significantly to both individual knowledge and that of the organization. Individual relates to people while organization relates to a group (Khadivar et al., 2007). SCM associations indicate that certification could be evaluated by using two sets of benefits (Tramarico et al., 2017) which include individual benefits (Hansen et al., 2002; Van Zyl, 2003; Lummus, 2007; Treem, 2013; Gammelgaard \& Larson, 2001). and organizational benefits (Gilbert, 2014; Bulkeley, 2006; Schoenherr et al., 2014b; Khadivar et al., 2007). Organizational knowledge is not intended to replace individual knowledge, but rather to complement it (Dalkir, 2005). In Table 4 the first four are individual benefits related to participants and the last four benefits are organizational benefits. 
Table 4. Individual and organizational benefits (Tramarico et al., 2017).

\begin{tabular}{|c|c|c|}
\hline Benefit & Description & Reference \\
\hline Individual recognition & $\begin{array}{l}\text { Recognition is appropriate to motivate behaviors such as inventiveness, } \\
\text { commitment, and initiative. }\end{array}$ & Hansen et al. (2002) \\
\hline Improve SCM knowledge & $\begin{array}{l}\text { The adoption and integration of what people know, how well people } \\
\text { communicate what they know and how quickly people learn new things, can } \\
\text { give a company a sustainable competitive advantage. }\end{array}$ & Van Zyl (2003) \\
\hline Credential recognition & $\begin{array}{l}\text { The credential allows certified individuals to demonstrate knowledge in the } \\
\text { professional activities of SCM. }\end{array}$ & Lummus (2007) \\
\hline $\begin{array}{l}\text { Validate of knowledge and } \\
\text { abilities }\end{array}$ & $\begin{array}{l}\text { Assess a worker's knowledge and abilities; the status characteristic is } \\
\text { perceived as relevant to an organizational task. }\end{array}$ & $\begin{array}{l}\text { Treem (2013), Gammelgaard \& } \\
\text { Larson (2001) }\end{array}$ \\
\hline $\begin{array}{l}\text { Common understanding of } \\
\text { vocabulary and processes }\end{array}$ & $\begin{array}{l}\text { Common understanding of a given concept and the terminology that would } \\
\text { be consistent in the company. }\end{array}$ & Lummus (2007) \\
\hline Use of best practices & $\begin{array}{l}\text { Methods that have been found to be an effective mean for accomplishing } \\
\text { goals and that can be used or adapted. }\end{array}$ & Gilbert (2014), Bulkeley (2006) \\
\hline Improve company performance & $\begin{array}{l}\text { The capability to share explicit and tacit knowledge for the company enables } \\
\text { competitive performance. }\end{array}$ & Schoenherr et al. (2014b) \\
\hline $\begin{array}{l}\text { Proven knowledge and } \\
\text { organizational skills }\end{array}$ & $\begin{array}{l}\text { Focus on supporting an individual to be more effective at work and to } \\
\text { operate better in groups and in the organization. }\end{array}$ & Khadivar et al. (2007) \\
\hline
\end{tabular}

These benefits were adopted as criteria to develop a multi-criteria analysis proposal of professional education programs.

\section{Methodology}

AHP is one of the leading MCDM methods (Wallenius et al., 2008; Tramarico et al., 2015). AHP was developed by Prof. Thomas Saaty in the 1970's while he was directing research projects for the Arms Control and Disarmament Agency at the United States Department of State (Saaty, 1980).

Originally (Saaty, 1977), AHP consisted of hierarchy structuring, relative measurement (pairwise comparisons between criteria and between alternatives), and distributive synthesis (priorities are normalized, i.e., they sum equal to one). Foundations of AHP include the Fundamental Scale of Absolute Numbers (Saaty, 2010), generating a pairwise comparison matrix $A$, in the sequence, using Linear Algebra concepts, as the eigenvector $(w)$, and eigenvalue $\left(\lambda_{\max }\right)$, it is possible to get their relative priorities.

In AHP, priorities are obtained through application of the Perron-Frobenius theorem (Saaty, 1977) as presented in (1).

$$
\mathrm{Aw}=\lambda_{\max } \mathrm{w}
$$

The consistency among the comparisons is an important propriety for $A$. If $A$ has consistent comparisons, then $a_{i j}=w_{i} / w_{j}$ for ${ }_{i, j}=1,2, \ldots n$, where $n$ is the order of $A$, and this way, $a_{i j}=a_{i k} a_{k j}$

If $A$ is not a $100 \%$ consistent matrix, then $\lambda_{\max }>n$. The consistency index, Cl, calculated by (2), as a measure of the distance between $\lambda_{\max }$ and $n$ :

$$
\mathrm{CI}=\left(\lambda_{\max }-\mathrm{n}\right) /(\mathrm{n}-1)
$$

CR, obtained with (3) also considers a random index Rl, associated to $n$. If CR is greater than 0.10 , a review on the comparisons may be necessary (Saaty, 2010).

\section{$\mathrm{CR} \mathrm{CI} / \mathrm{RI}$}

The AHP application can be summarized using four steps, including: Hierarchy structuring, pairwise comparisons, consistency checking, and synthesis of results.

Absolute measurement, also known as "rating" (Saaty, 1986) is one useful advance in AHP practice. In absolute measurement, alternatives are compared with standard levels, instead of pairwise comparisons. Relative measurement has been more applied than ratings. Since in relative measurement alternatives must be pairwise compared, Saaty \& Ozdemir (2003) suggest their number be less-than or equal to nine, that is, "seven, plus or minus two". In absolute measurement, there is no boundary for the set of alternatives. With alternatives being compared to each other, two by two (relative measurement), some historical trends could be kept in 
mind. Comparing alternatives with a standard (absolute measurement) provided a less partial or measurement in some cases (Salomon et al., 2016).

Another advance for original AHP comes with the "ideal synthesis" (Millet \& Saaty, 2000). With ideal synthesis, the sum of priority vectors components will not be equal to one. In this mode, the highest priority regarding each criterion will be equal to one. Normalizing priorities creates a dependency among priorities. However, if an old alternative was deleted or if a new one was inserted normalized priorities can lead to changes in the rank of alternatives, known as rank reversal.

The AHP application can be summarized in a few steps, including hierarchy construction, pairwise comparison, consistency checking, and results. In our research, the proposed flowchart (Figure 4) is adapted from (De Felice \& Petrillo, 2013) and modified for our research.

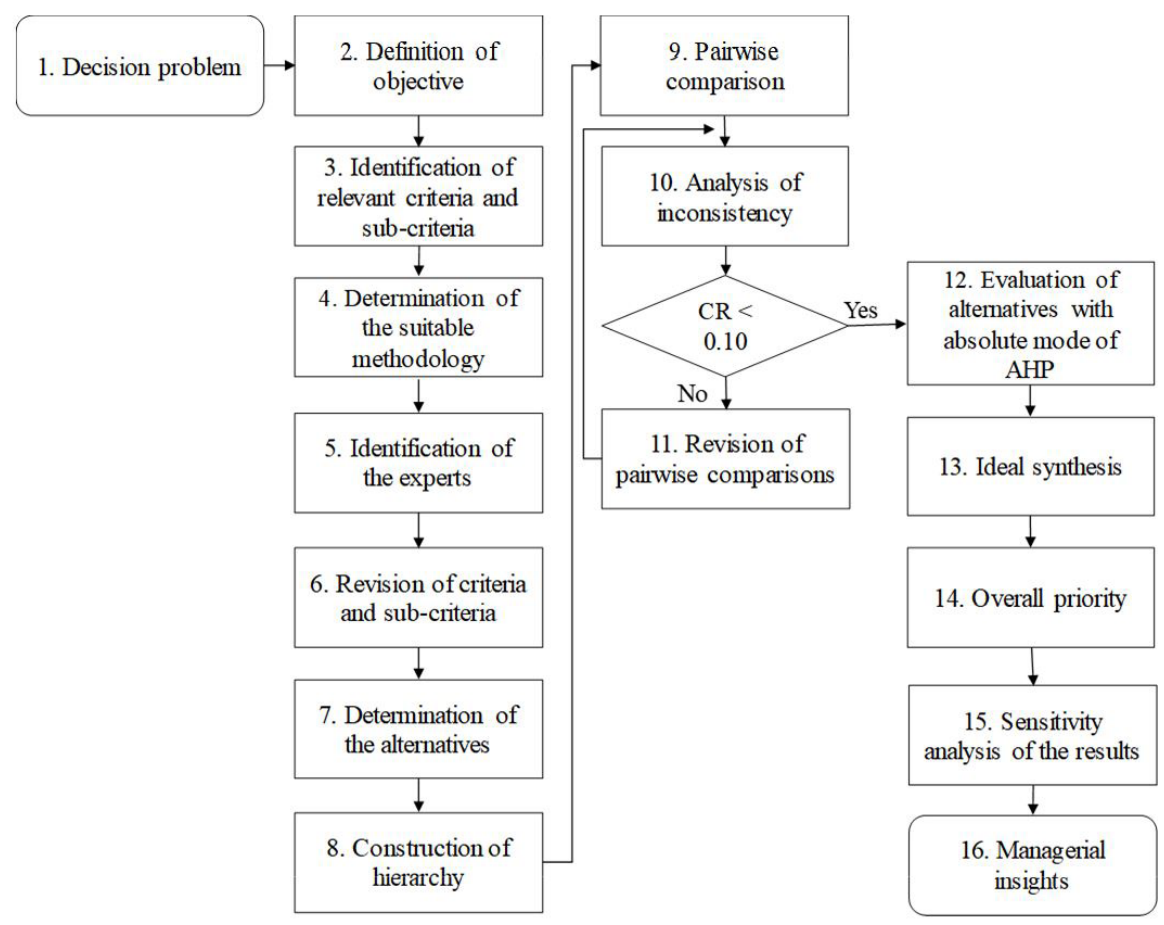

Figure 4. Flowchart of methodological approach (Adapted from: De Felice \& Petrillo, 2013).

\section{Application}

This section presents the analysis of professional education programs offered by SCM associations that are dedicated to developing, sharing knowledge and contributing to SCM field.

The research presented in this paper was conducted through assessment sessions with experts and SCM managers, who work in a major chemical plant that belongs to a multinational group, located in the State of Sao Paulo, Brazil. Having a large portfolio of products, the company has offered important contributions to the segment of products for chemicals, plastic, oil and gas. The proposal comprises analyzing six professional education programs (Table 3) offered by leading SCM associations. Also, included in the proposal analysis is the CPIM program described by Lummus (2007). The experts who took part in the assessment are business consultants and all of them have at least 15 years of experience in conducting projects and trainings on different topics such as Demand Management, Materials Management, Production Management and Supply Network Planning in chemical plants located in North America and South America. These experts have at least a bachelor's degree in Production Engineering, Business Administration or Chemistry. They participated in the assessment and results validation by face to face method. All experts and SCM managers are well aware of the SCM professional education programs presented in Table 3.

In this stage, AHP was applied and Web-Based Software named Comparion Suite, version 5.4 developed by Expert Choice, Inc. was used as a software (Incorporated Expert Choice, Inc., 2015). 
AHP uses a hierarchy structure to model the complexity and interactions between the various elements involved in a problem. In this work, the first hierarchical level "Analysis of professional education programs" was considered as the objective of the problem. The two criteria considered were benefits for the individual and the benefits for organization (Figure 5). The sub-criteria include individual recognition, improve SCM knowledge, professional certification, validation of knowledge and skills, common understanding of vocabulary and processes, best practices, improved company performance, and proven knowledge and organizational skills (Tramarico et al., 2017). Sub-criteria were confirmed by the experts. The alternatives were professional education program offered by leading SCM associations: ACPF, CPIM, CPSM, CSCM, ECL, and SC PRO (Table 3). Figure 5 presents the AHP hierarchy adopted in this work.

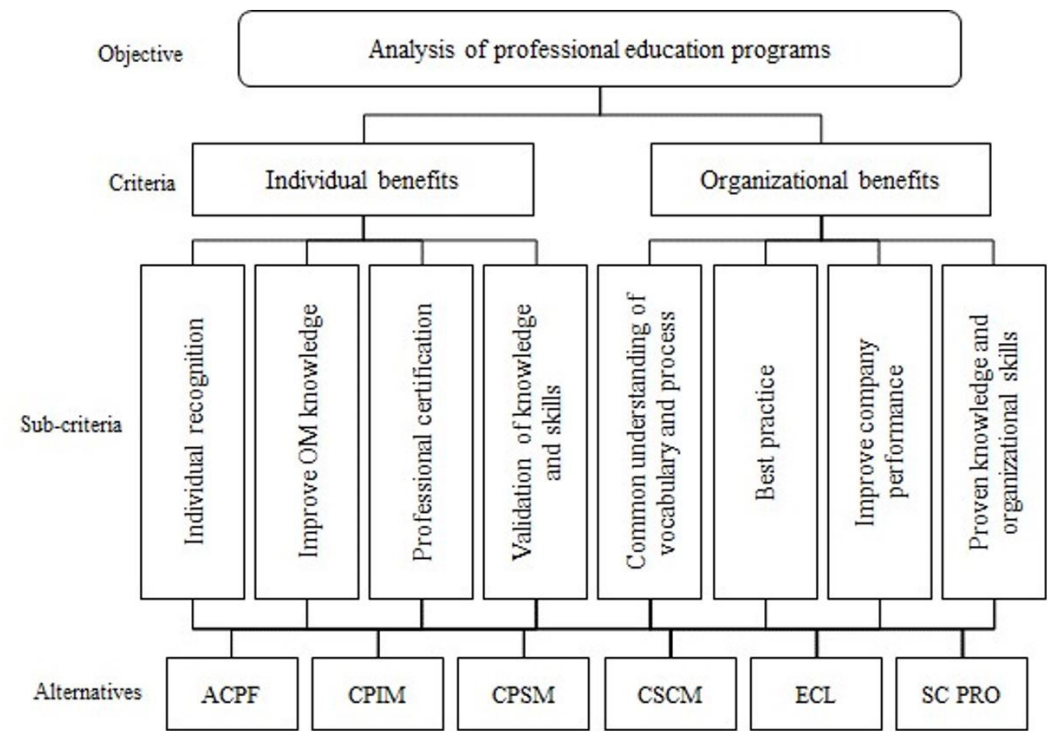

Figure 5. Hierarchy for professional education programs analysis.

Pairwise comparisons among the sub-criteria (Table 5) individual benefits and (Table 6) organizational benefits were obtained by consensus with the experts. The data was collected and processed in spreadsheets. Note decimal values in some comparisons, as recommended by Saaty (2010). Priorities were obtained by normalizing the right eigenvector of the comparisons matrix.

Table 5. Priorities of individual benefits.

\begin{tabular}{lccccc}
\hline \multicolumn{1}{c}{ Sub-criteria } & IR & IK & PC & VK & Priority \\
\hline IR (Individual recognition) & 1 & 0.9 & 0.9 & 2.4 & $27.5 \%$ \\
IK (Improve SCM knowledge & $1 / 0.9$ & 1 & 1 & 2.7 & $30.6 \%$ \\
PC (Professional certification) & $1 / 0.9$ & 1 & 1 & 2.7 & $30.6 \%$ \\
VK (Validation of knowledge and skills) & $1 / 2.4$ & $1 / 2.7$ & $1 / 2.7$ & 1 & $11.3 \%$ \\
\hline
\end{tabular}

Table 6. Priorities of organizational benefits.

\begin{tabular}{lccccc}
\hline \multicolumn{1}{c}{ Sub-criteria } & VP & BP & CP & OS & Priority \\
\hline VP (Common understanding of vocabulary and processes) & 1 & 1 & 0.9 & 2.2 & $28.1 \%$ \\
BP (Best practices) & 1 & 1 & 0.9 & 2.2 & $28.1 \%$ \\
CP (Improve company performance) & $1 / 0.9$ & $1 / 0.9$ & 1 & 2.7 & $31.1 \%$ \\
OS (Proven knowledge and organizational skills) & $1 / 2.2$ & $1 / 2.2$ & $1 / 2.7$ & 1 & $12.7 \%$ \\
\hline
\end{tabular}

None of the experts were inconsistent beyond 10\%. Pairwise comparison part of the interview, hence, was completed in one meeting and there was no need eliciting further judgments to identify reasons of inconsistency. The main focus of the study was identifying the importance of a criteria over another one: consistency ratios were instrumental identifying real importance rating exists in experts' minds. 
In AHP applications the experts can give judgments in numerical scale entering the values between 1 and 9 or use linguistic mode with semantic terms such as "demonstrated importance," "extreme importance," etc. Experts are guided to give their judgments in verbal mode rather than in numerical scale since verbal comparison mode dominates numerical one based on perceived ease of use and accuracy criteria (Karpak \& Topçu, 2010; Millet, 1997).

In Table 5, from the comparison of sub-criteria "individual recognition" and "validation of knowledge and skills" the experts judged the sub-criterion "individual recognition" as more important compared to "validation of knowledge and skills."

The professional education programs were analyzed using absolute measurement and ideal synthesis (Millet \& Saaty, 2000). Ideal synthesis is indicated in AHP applications if the main objective is to identify the best alternative. The combination of absolute measurement with ideal synthesis has the advantage of not allowing reverse order or reversal ranking, a critique initially associated with AHP, but present in several MCDM methods, such as ELECTRE and TOPSIS, for example (Triantaphyllou, 2010).

The absolute measurement is used to rank independent alternatives one at a time in terms of rating intensities for each of the criteria. The level of performance corresponding to the attributes in linguistic scales varies from "Poor" to "Excellent". The reason for the adoption of the absolute measurement is because it has the potential to significantly reduce conflicts in decision making processes (De Felice \&t Petrillo, 2013).

Note that priorities are normalized to highest priority be equal to one (ideal synthesis). Company's experts agreed with the levels and priorities presented in Table 7.

Table 7 presents the intensity levels, or the quality degrees, set for the analysis of professional education programs alternatives.

Table 7. Priority scale used for absolute measurement of the six programs.

\begin{tabular}{lccccccc}
\hline \multicolumn{1}{c}{ Level } & L1 & L2 & L3 & L4 & L5 & Eigenvector & Priority \\
\hline L1 (Excellent) & 1 & 1.2 & 1.5 & 2 & 4 & 1.70 & 1 \\
L2 (Very good) & $1 / 1.2$ & 1 & 1.2 & 1.7 & 3.3 & 1.41 & 0.83 \\
L3 (Good to very good) & $1 / 1.5$ & $1 / 1.2$ & 1 & 1.3 & 2.7 & 1.14 & 0.67 \\
L4 (Good) & $1 / 2$ & $1 / 1.7$ & $1 / 1.3$ & 1 & 2 & 0.85 & 0.50 \\
L5 Poor to good) & $1 / 4$ & $1 / 3.3$ & $1 / 2.7$ & $1 / 2$ & 1 & 0.43 & 0.25 \\
L6 (Poor) & 0 & 0 & 0 & 0 & 0 & 0 & 0 \\
\hline
\end{tabular}

The qualitative evaluation of professional education programs was performed for all sub-criteria (Table 8) of individual benefits and organizational benefits.

In Table 9, the priorities from Table 7 replace the qualitative judgments in Table 8.

Table 8. Qualitative evaluation of professional education programs.

\begin{tabular}{lllllllll}
\hline \multicolumn{1}{c}{ Programs/Sub-criteria } & IR & IK & PC & VK & VP & BP & CP & OS \\
\hline ACPF (Advanced Certified Professional Forecaster) & $\mathrm{L} 2$ & $\mathrm{~L} 2$ & $\mathrm{~L} 2$ & $\mathrm{~L} 3$ & $\mathrm{~L} 1$ & $\mathrm{~L} 4$ & $\mathrm{~L} 2$ & $\mathrm{~L} 2$ \\
CPIM (Certified Production and Inventory Management) & $\mathrm{L} 2$ & $\mathrm{~L} 1$ & $\mathrm{~L} 1$ & $\mathrm{~L} 2$ & $\mathrm{~L} 1$ & $\mathrm{~L} 2$ & $\mathrm{~L} 2$ & $\mathrm{~L} 2$ \\
CPSM (Certified Professional in Supply Management) & $\mathrm{L} 4$ & $\mathrm{~L} 3$ & $\mathrm{~L} 4$ & $\mathrm{~L} 4$ & $\mathrm{~L} 2$ & $\mathrm{~L} 3$ & $\mathrm{~L} 3$ & $\mathrm{~L} 4$ \\
CSCM (Certified Supply Chain Manager) & $\mathrm{L} 4$ & $\mathrm{~L} 3$ & $\mathrm{~L} 4$ & $\mathrm{~L} 4$ & $\mathrm{~L} 4$ & $\mathrm{~L} 4$ & $\mathrm{~L} 4$ & $\mathrm{~L} 4$ \\
ECL (European Certified Logistician) & $\mathrm{L} 4$ & $\mathrm{~L} 3$ & $\mathrm{~L} 4$ & $\mathrm{~L} 4$ & $\mathrm{~L} 2$ & $\mathrm{~L} 1$ & $\mathrm{~L} 4$ & $\mathrm{~L} 4$ \\
SC PRO (Supply Chain Professiona) & $\mathrm{L} 2$ & $\mathrm{~L} 2$ & $\mathrm{~L} 3$ & $\mathrm{~L} 2$ & $\mathrm{~L} 1$ & $\mathrm{~L} 3$ & $\mathrm{~L} 2$ & $\mathrm{~L} 2$ \\
\hline
\end{tabular}

Table 9. Quantitative evaluation of professional education programs.

\begin{tabular}{lcccccccc}
\hline \multicolumn{1}{c}{ Program } & IR & IK & PC & VK & VP & BP & CP & OS \\
\hline ACPF & 0.83 & 0.83 & 0.83 & 0.67 & 1 & 0.50 & 0.83 & 0.83 \\
CPIM & 0.83 & 1 & 1 & 0.83 & 1 & 0.83 & 0.83 & 0.83 \\
CPSM & 0.50 & 0.67 & 0.50 & 0.50 & 0.83 & 0.67 & 0.67 & 0.50 \\
CSCM & 0.50 & 0.67 & 0.50 & 0.50 & 0.50 & 0.50 & 0.50 & 0.50 \\
ECL & 0.50 & 0.67 & 0.50 & 0.50 & 0.83 & 1 & 0.50 & 0.50 \\
SC PRO & 0.83 & 0.83 & 0.67 & 0.83 & 1 & 0.67 & 0.83 & 0.83 \\
\hline
\end{tabular}


All the experts considered that individual benefits have the same priority (50\%) of organizational benefits, the local priorities of the sub-criteria (Tables 6 and 7) must be divided by 2, to obtain the overall priority of each sub-criterion. For instance, overall priority of $\mathrm{IR}$ is $27.5 \% / 2=13.8 \%$.

The same procedure must be done for IK, PC, VK, VP, BP, CP and OS, resulting in Table 10. Overall priorities for sub-criteria associated with individual and organizational benefits indicated there is no significate difference (all them are about 15\%) among IK, PC and CP. An interpretation of these results is that the most valuable characteristics desirable for professional education programs are the ability to improve company performance, recognition of professional certification, and improvement of SCM knowledge. Value of sub-criteria IR, VP and BP are lower, but not so much (13\%-14\%).

Table 10. Overall priority.

\begin{tabular}{lc}
\hline \multicolumn{1}{c}{ Sub-criteria } & Overall priority \\
\hline Individual benefits & $50.0 \%$ \\
IR (Individual recognition) & $13.8 \%$ \\
IK (Improve SCM knowledge) & $15.3 \%$ \\
PC (Professional certification) & $15.3 \%$ \\
VK (Validation of knowledge and skills) & $5.6 \%$ \\
Organizational benefits & $50.0 \%$ \\
VP (Common understanding of vocabulary and processes) & $14.1 \%$ \\
BP (Best practices) & $14.1 \%$ \\
CP (Improve company performance) & $15.5 \%$ \\
OS (Proven knowledge and organizational skills) & $6.3 \%$ \\
\hline
\end{tabular}

Using the quantitative evaluation of professional education programs (Table 8) and overall priority (Table 9) we obtain the overall evaluation of the professional education programs (Table 10). The ACPF calculation (4) for individual benefits:

$$
\mathrm{ACPF}=0.83 \times 13.8 \%+0.83 \times 15.3 \%+0.83 \times 15.3 \%+0.67 \times 5.6 \%=0.41
$$

The same procedure (5) was used to calculate the organizational benefits:

$$
\mathrm{ACPF}=1.0 \times 14.1 \%+0.5 \times 14.1 \%+0.83 \times 15.5 \%+0.83 \times 6.3 \%=0.39
$$

Thus, summing up the results (6), we have the overall evaluation:

$$
0.41+0.39=0.80
$$

The same procedure was used to calculate CPIM, CPSM, CSCM, ECL and SC PRO programs. In Table 11, the results of the overall evaluation are presented.

Table 11. Overall evaluation of professional education programs.

\begin{tabular}{cc}
\hline Program & Overall evaluation \\
\hline ACPF & 0.80 \\
CPIM & 0.91 \\
CPSM & 0.62 \\
CSCM & 0.53 \\
ECL & 0.64 \\
SC PRO & 0.81 \\
\hline
\end{tabular}

In Table 11, CPIM has obtained the highest score, and in the sequence of the others from high to low is: SC PRO, ACPF, ECL, CPSM and CSCM.

\section{Discussion and conclusions}

This work is an extension of an earlier research which evaluated APICS CPIM and concluded that certification finds target audience through new employees (Lummus, 2007). Lummus evaluated only APICS certification. This study contributes to the literature by proposing an analysis of professional education programs offered by 
leading SCM associations such as APICS, CSCMP, ISM and others from multiple perspectives including tangible and intangible benefits. AHP has been implemented in a variety of Operations Management decisions yet to the best knowledge of the authors it has not been applied in evaluation of professional education programs of SCM. This is the first application of AHP on the evaluation of variety of SCM training in companies.

This paper provides multiple insights for senior executives seeking to improve capabilities in their organizations through professional education program. Senior executives preferred CPIM education program and the research supported their decision, with 0.91 of overall priority. The next alternatives, SC PRO and ACPF, with respectively 0.81 and 0.80 , are also some good options for SCM education programs. Thus, the CPIM program gives the best benefits overall to individuals and their organizations. Knowledge such as this can be used in two ways. The first way is for organizations to pick the best program, CPIM, and send all employees there. But acknowledging perhaps that the programs focus on different skills, an organization might choose to broaden the skills it gets back by proportionately allocating the employees it sends for educational training among the top three programs: CPIM, SC PRO, and ACPF, since they seem to have a measurable advantage over the other three. This research encouraged the company to implement CPIM educations programs for other subsidiaries as well. Authors are planning to be instrumental in this endeavor.

The analysis considered the individual benefits to have the same priority (50\%) as the organizational benefits (i.e., the individual and organizational benefits were equally important).

Sensitivity analysis is performed to test the robustness of the results by changing the priorities of the benefits (Figure 6).

In Figure 6, the blue vertical line represents the original weight (50\%) and the red vertical line represents $(67 \%)$ for organizational benefits. However, whatever the weight for the organizational benefits is the CPIM program remained at the top. The SC PRO education program were more preferable than the ACPF program when organizational benefits are weighted beyond 50\%. The ECL, CPSM and CSCM education programs remained in the same position regardless of the weight given to organizational benefits.
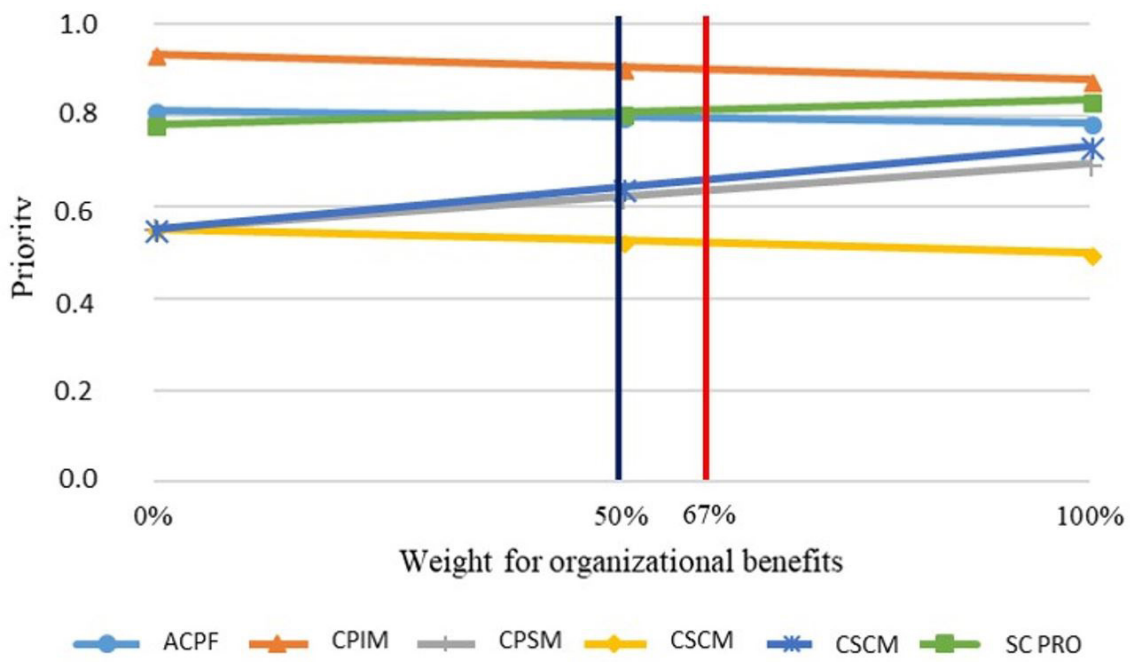

Figure 6. Sensitivity analysis of organizational benefits.

The result of the two-dimensional sensitivity analysis (Figure 7) illustrates that, among the SCM professional education programs evaluated, the CPIM education program was considered the best for this company. Concluding, in this company CPIM contributes most to the individual and organizational benefits.

The presented analysis is not without limitations. This result cannot be simply generalized as future studies needed to extend the findings to other organizations. However, the same framework as well as the same methodology can be used to evaluate multiple professional education programs. We assert that professional educational programs have to be compared from multiple perspectives therefore a multiple criteria approach has to be used. Since some of these multiple criteria are quantitative and some others are qualitative AHP and/ or its variations seems to be among the most appropriate methodologies. 


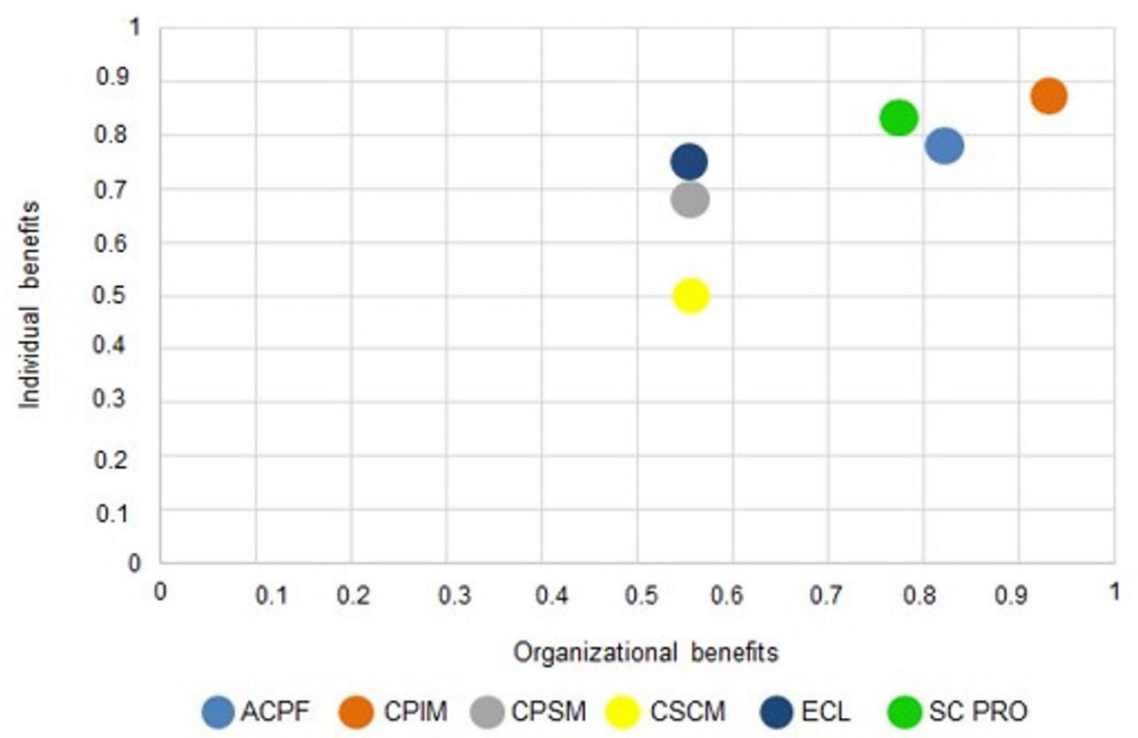

Figure 7. Two-dimensional sensitivity analysis.

We just considered organizational and individual benefits. Further research might include a new approach BOCR (Benefits, Opportunities, Costs, and Risks) to analyze the professional education program's tasks and objectives. There may be dependence and interrelations between criteria, sub-criteria and even among the alternatives. For these situations ANP (Analytic Network Process) may be more preferable approach. Saaty (2010) developed The ANP methodology for decisions with dependence and feedback. Variety of examples that use this methodology for SCM decisions are given in Saaty \& Ozdemir (2005). It would be interesting to compare BOCR approach results with AHP results with ranking obtained via ANP. Though ANP is more suitable when there are dependencies among the criteria and/or alternatives it requires quite a few more pairwise comparison than AHP. It is a challenge how to elicit pairwise comparisons without causing expert fatigue and how to expedite decision making without loss of validity. Sometimes decision makers prefer simplicity over precision.

Another possible approach is to carry out an evaluation of the professional education program in the long term, based on the tangible aspects of effectiveness and efficiency through another MCDM method.

\section{Acknowledgements}

The authors express their acknowledgments to Sao Paulo Research Foundation (FAPESP Grant No. 2017/22963-6).

\section{References}

Ahire, S. L. (2001). Linking operations management students directly to the real world. Interfaces, 31(5), 104-120. http://dx.doi. org/10.1287/inte.31.5.104.9653.

Alfalla-Luque, R., Medina-López, C., \&t Arenas-Márquez, F. J. (2011). A step forward in operations management training: student visions and their response to different learning environments. Cuadernos de Economía y Dirección de la Empresa, 14(1), 40-52. http:// dx.doi.org/10.1016/j.cede.2011.01.002.

Association for Supply Chain Management - APICS. (2018). Certified in production and inventory management. Retrieved in 2018, April 17, from http://www.apics.org/cpim

Brandon-Jones, A., Lewis, M., Verma, R., \&t Walsman, M. C. (2016). Examining the characteristics and managerial challenges of professional services: an empirical study of management consultancy in the travel, tourism, and hospitality sector. Journal of Operations Management, 42(1), 9-24. http://dx.doi.org/10.1016/j.jom.2016.03.007.

Bulkeley, H. (2006). Urban sustainability: learning from best practice? Environment \&t Planning A, 38(6), 1029-1044. http://dx.doi. org/10.1068/a37300.

Camm, J. D., Cochran, J. J., \&t Gorman, M. F. (2014). A survey of academic use of Interfaces. Interfaces, 45(2), 187-195. http://dx.doi. org/10.1287/inte.2014.0756.

Cannon, J. P., Doney, P. M., Mullen, M. R., \&t Petersen, K. J. (2010). Building long-term orientation in buyer-supplier relationships: the moderating role of culture. Journal of Operations Management, 28(6), 506-521. http://dx.doi.org/10.1016/j.jom.2010.02.002. 
Centre for Science and Technology Studies. (2018). CitNetExplorer analyzing citation patterns in scientific literature. Version: 1.0. Leiden: Centre for Science and Technology Studies.

Coltman, T., \& Devinney, T. M. (2013). Modeling the operational capabilities for customized and commoditized services. Journal of Operations Management, 31(7-8), 555-566. http://dx.doi.org/10.1016/j.jom.2013.09.002.

Cottrill, K. (2010). Are you prepared for the supply chain talent crisis? (pp. 1-11). Cambridge: MIT Center for Transportation and Logistics.

Dalkir, K. (2005). Knowledge management in theory and practice. Burlington: Elsevier Butterworth-Heinemann.

De Felice, F., \&t Petrillo, A. (2013). Absolute measurement with analytic hierarchy process: a case study for ltalian racecourse. International Journal of Applied Decision Sciences, 6(3), 209-227. http://dx.doi.org/10.1504/1JADS.2013.054931.

De Treville, S., \& Van Ackere, A. (2006). Equipping students to reduce lead times: the role of queuing-theory-based modeling. Interfaces, 36(2), 165-173. http://dx.doi.org/10.1287/inte.1050.0188.

Dey, P. K., \& Cheffi, W. (2013). Green supply chain performance measurement using the analytic hierarchy process: a comparative analysis of manufacturing organisations. Production Planning and Control, 24(8-9), 702-720. http://dx.doi.org/10.1080/095372 87.2012.666859.

Fawcett, S. E., \&t Rutner, S. M. (2014). A longitudinal view of supply chain education: assessing the challenge of retaining relevance in today's dynamic marketplace. International Journal of Logistics Management, 25(1), 180-201. http://dx.doi.org/10.1108/1JLM07-2012-0061.

Fawcett, S., Jin, Y. H., Fawcett, A., \& Bernardes, E. (2018). Technological game changers: convergence, hype, and evolving supply chain design. Production, 28(0), e20180002. http://dx.doi.org/10.1590/0103-6513.20180002.

Feisel, E., Hartmann, E., \& Giunipero, L. (2011). The importance of the human aspect in the supply function: strategies for developing PSM proficiency. Journal of Purchasing and Supply Management, 17(1), 54-67. http://dx.doi.org/10.1016/j.pursup.2010.07.001.

Gammelgaard, B., Ct Larson, P. D. (2001). Logistics skills and competencies for supply chain management. Journal of Business Logistics, 22(2), 27-50. http://dx.doi.org/10.1002/j.2158-1592.2001.tb00002.x.

Gibson, T., Kerr, D., \& Fisher, R. (2016). Accelerating supply chain management learning: identifying enablers from a university-industry collaboration. Supply Chain Management, 21(4), 470-484. http://dx.doi.org/10.1108/SCM-10-2014-0343.

Gilbert, L. (2014). Social Justice and the "Green" city. Urbe. Revista Brasileira de Gestão Urbana, 6(2), 158-169. http://dx.doi.org/10.7213/ urbe.06.002.SE01.

Hansen, F., Smith, M., \& Hansen, R. B. (2002). Rewards and recognition in employee motivation. Compensation and Benefits Review, 34(5), 64-72. http://dx.doi.org/10.1177/0886368702034005010.

Hirsch, J. E. (2005). An index to quantify an individual's scientific research output. Proceedings of the National Academy of Sciences of the United States of America, 102(46), 16569-16572. http://dx.doi.org/10.1073/pnas.0507655102. PMid:16275915.

Ho, W., \& Ma, X. (2018). The state-of-the-art integrations and applications of the analytic hierarchy process. European Journal of Operational Research, 267(2), 399-414. http://dx.doi.org/10.1016/j.ejor.2017.09.007.

Hohenstein, N. O., Feisel, E., \& Hartmann, E. (2014). Human resource management issues in supply chain management research: a systematic literature review from 1998 to 2014. International Journal of Physical Distribution \& Logistics Management, 44(6), 434463. http://dx.doi.org/10.1108/IJPDLM-06-2013-0175.

Hopp, W. J., Iravani, S. M., \& Yuen, G. Y. (2007). Operations systems with discretionary task completion. Management Science, 53(1), 61-77. http://dx.doi.org/10.1287/mnsc.1060.0598.

lbrahim, S. E. (2010). An alternative methodology for formulating an operations strategy: the case of BTC-Egypt. Management Decision, 48(6), 868-893. http://dx.doi.org/10.1108/00251741011053442.

Incorporated Expert Choice, Inc. (2015). Web-based software comparion suite. Version: 5.4. Arlinton: Incorporated Expert Choice, Inc.

International Society on MCDM. (2018). Mission of the society. Retrieved in 2018, April 6, from http://www.mcdmsociety.org/content/ mission-society

lshizaka, A., \&t Nemery, P. (2013). Multi-criteria decision analysis: methods and software. West Sussex: John Wiley \&t Sons. http://dx.doi. org/10.1002/9781118644898.

Jakhar, S. K. (2015). Performance evaluation and a flow allocation decision model for a sustainable supply chain of an apparel industry. Journal of Cleaner Production, 87(1), 391-413. http://dx.doi.org/10.1016/j.jclepro.2014.09.089.

Karpak, B., \& Topçu, 1. (2010). Small medium manufacturing enterprises in Turkey: an analytic network process framework for prioritizing factors affecting success. International Journal of Production Economics, 125(1), 60-70. http://dx.doi.org/10.1016/j.ijpe.2010.01.001.

Khadivar, A., Zadeh, A. R., Khani, M., \&t Jalali, S. M. J. (2007). A conceptual model for knowledge flow in supply chain. In IEEE International Conference on Industrial Engineering and Engineering Management (pp. 352-356). USA: IEEE. http://dx.doi.org/10.1109/ IEEM.2007.4419210.

Kotzab, H., Teller, C., Bourlakis, M., \& Wünsche, S. (2018). Key competences of logistics and SCM professionals: the lifelong learning perspective. Supply Chain Management, 23(1), 50-64. http://dx.doi.org/10.1108/SCM-02-2017-0079.

Krainer, C. W. M., Krainer, J. A., \& Romano, C. A. (2018). Interorganizational relationships in the Brazilian construction industry supply chain. Production, 28(0), e20170075. http://dx.doi.org/10.1590/0103-6513.20170075.

Lau, H., Nakandala, D., Samaranayake, P., \& Shum, P. (2016). A hybrid multi-criteria decision model for supporting customer-focused profitability analysis. Industrial Management \&t Data Systems, 116(6), 1105-1130. http://dx.doi.org/10.1108/IMDS-10-2015-0410.

Lewis, M. A., \& Brown, A. D. (2012). How different is professional service operations management? Journal of Operations Management, 30(1-2), 1-11. http://dx.doi.org/10.1016/j.jom.2011.04.002.

Lummus, R. R. (2007). The role of APICS in professionalizing operations management. Journal of Operations Management, 25(2), 336345. http://dx.doi.org/10.1016/j.jom.2006.11.004.

Lutz, H., \& Birou, L. (2013). Logistics education: a look at the current state of the art and science. Supply Chain Management, 18(4), 455-467. http://dx.doi.org/10.1108/SCM-08-2012-0269. 
Maloni, M. J., \& Carter, C. R. (2018). Publication Productivity in the SCM Discipline: 2014-2016. Transportation Journal, 571), 1-23. http://dx.doi.org/10.5325/transportationj.57.1.0001.

Mentzer, J. T., Stank, T. P., \& Esper, T. L. (2008). Supply chain management and its relationship to logistics, marketing, production, and operations management. Journal of Business Logistics, 29(1), 31-46. http://dx.doi.org/10.1002/j.2158-1592.2008.tb00067.x.

Millet, 1. (1997). The effectiveness of alternative preference elicitation methods in the analytic hierarchy process. Journal of Multi-Criteria Decision Analysis, 6(1), 41-51. http://dx.doi.org/10.1002/(SICI) 1099-1360(199701)6:1<41::AID-MCDA122>3.0.C0;2-D.

Millet, 1., \& Saaty, T. L. (2000). On the relativity of relative measures-accommodating both rank preservation and rank reversals in the AHP. European Journal of Operational Research, 121(1), 205-212. http://dx.doi.org/10.1016/S0377-2217(99)00040-5.

Olson, J. E. (2005). Top-25-business-school professors rate journals in operations management and related fields. Interfaces, 35(4), 323-338. http://dx.doi.org/10.1287/inte.1050.0149.

Pittman, P. H., \&t Atwater, J. B. (Ed.), (2016). APICS dictionary (15th ed.). Chicago: APICS.

Rai, A., \& Hornyak, R. (2013). The impact of sourcing enterprise system use and work process interdependence on sourcing professionals' job outcomes. Journal of Operations Management, 31(6), 474-488. http://dx.doi.org/10.1016/j.jom.2013.07.005.

Ricker, M. (2017). Letter to the Editor: about the quality and impact of scientific articles. Scientometrics, 111(3), 1851-1855.

Rossetti, C. L., \& Dooley, K. J. (2010). Job types in the supply chain management profession. The Journal of Supply Chain Management, 46(3), 40-56. http://dx.doi.org/10.1111/j.1745-493X.2010.03197.x.

Saaty, T. L. (1977). A scaling method for priorities in hierarchical structures. Journal of Mathematical Psychology, 15(3), 234-281. http:// dx.doi.org/10.1016/0022-2496(77)90033-5.

Saaty, T. L. (1980). The analytic hierarchy process: planning, priority setting, resource allocation. New York: McGraw-Hill.

Saaty, T. L. (1986). Absolute and relative measurement with the AHP. The most livable cities in the United States. Socio-Economic Planning Sciences, 20(6), 327-331. http://dx.doi.org/10.1016/0038-0121(86)90043-1.

Saaty, T. L. (2010). Principia mathematica decernendi: mathematical principles of decision-making. Pittsburgh: RWS.

Saaty, T. L., \& Ozdemir, M. S. (2003). Why the magic number seven plus or minus two. Mathematical and Computer Modelling, 38(3-4), 233-244. http://dx.doi.org/10.1016/S0895-7177(03)90083-5.

Saaty, T. L., \& Ozdemir, M. S. (2005). The encyclicon: a dictionary of decisions with dependence and feedback based on the analytic networking process. Pittsburg: RWS.

Salomon, V. A. P., Tramarico, C. L., \& Marins, F. A. S. (2016). Analytic hierarchy process applied to supply chain management. In F. De Felice, A. Petrillo \& T. Saaty (Eds.), Applications and theory of analytic hierarchy process: decision making for strategic decisions. Hijeka: InTech. http://dx.doi.org/10.5772/64022.

Scavarda, L. F., Hellingrath, B., Kreuter, T., Thomé, A. M. T., Seeling, M. X., Fischer, J.-H., \&t Mello, R. (2017). A case method for Sales and Operations Planning: a learning experience from Germany. Production, 27(spe), e20162199. http://dx.doi.org/10.1590/01036513.219916.

Schellekens, A., Paas, F., \&t van Merriënboer, J. J. (2003). Flexibility in higher professional education: a survey in business administration programmes in the Netherlands. Higher Education, 45(3), 281-305. http://dx.doi.org/10.1023/A:1022986105505.

Schellekens, A., Paas, F., Verbraeck, A., \&t van Merriënboer, J. J. (2010a). Designing a flexible approach for higher professional education by means of simulation modelling. The Journal of the Operational Research Society, 61(2), 202-210. http://dx.doi.org/10.1057/ jors.2008.133.

Schellekens, A., Paas, F., Verbraeck, A., \& Van Merriënboer, J. J. (2010b). Flexible programmes in higher professional education: expert validation of a flexible educational model. Innovations in Education and Teaching International, 47(3), 283-294. http://dx.doi.org /10.1080/14703297.2010.498179.

Schoenherr, T., \& Swink, M. (2012). Revisiting the arcs of integration: Cross-validations and extensions. Journal of Operations Management, 30(1-2), 99-115. http://dx.doi.org/10.1016/j.jom.2011.09.001.

Schoenherr, T., Griffith, D. A., \&t Chandra, A. (2014b). Knowledge management in supply chains: the role of explicit and tacit knowledge. Journal of Business Logistics, 35(2), 121-135. http://dx.doi.org/10.1111/jbl.12042.

Schoenherr, T., Modi, S. B., Talluri, S., \&t Hult, G. T. M. (2014a). Antecedents and performance outcomes of strategic environmental sourcing: an investigation of resource-based process and contingency effects. Journal of Business Logistics, 35(3), 172-190. http:// dx.doi.org/10.1111/jbl.12052.

Sodhi, M. S., Son, B. G., \& Tang, C. S. (2008). ASP, the art and science of practice: what employers demand from applicants for MBA-level supply chain jobs and the coverage of supply chain topics in MBA courses. Interfaces, 38(6), 469-484. http://dx.doi.org/10.1287/ inte.1080.0377.

Stouthuysen, K., Slabbinck, H., \& Roodhooft, F. (2012). Controls, service type and perceived supplier performance in interfirm service exchanges. Journal of Operations Management, 30(5), 423-435. http://dx.doi.org/10.1016/j.jom.2012.01.002.

Subramanian, N., \&t Ramanathan, R. (2012). A review of applications of Analytic Hierarchy Process in operations management. International Journal of Production Economics, 138(2), 215-241. http://dx.doi.org/10.1016/j.jpe.2012.03.036.

Swanson, D., Goel, L., Francisco, K., \&t Stock, J. (2017). Applying theories from other disciplines to logistics and supply chain management: a systematic literature review. Transportation Journal, 56(3), 299-356. http://dx.doi.org/10.5325/transportationj.56.3.0299.

Tramarico, C. L., Salomon, V. A. P., \& Marins, F. A. S. (2015). Analytic hierarchy process and supply chain management: a bibliometric study. Procedia Computer Science, 55, 441-450. http://dx.doi.org/10.1016/j.procs.2015.07.005.

Tramarico, C. L., Salomon, V. A. P., \& Marins, F. A. S. (2017). Multi-criteria assessment of the benefits of a supply chain management training considering green issues. Journal of Cleaner Production, 142, 249-256. http://dx.doi.org/10.1016/j.jclepro.2016.05.112.

Treem, J. W. (2013). Technology use as a status cue: the influences of mundane and novel technologies on knowledge assessments in organizations. Journal of Communication, 63(6), 1032-1053. http://dx.doi.org/10.1111/jcom.12061.

Triantaphyllou, E. (2010). Multi-criteria decision-making methods: a comparative study. Dordrecht: Kluwer. 
Van Eck, N. J., \& Waltman, L. (2014). Systematic retrieval of scientific literature based on citation relations: introducing the CitNetExplorer Tool (pp. 13-20). USA: BIR@ ECIR.

Van Zyl, C. (2003). Supply chain knowledge management adoption increases overall efficiency and competitiveness. South African Journal of Information Management, 5(4), 1-15. http://dx.doi.org/10.4102/sajim.v5i4.381.

Varthanan, P. A., Murugan, N., Kumar, G. M., \& Parameswaran, S. (2012). Development of simulation-based AHP-DPSO algorithm for generating multi-criteria production-distribution plan. International Journal of Advanced Manufacturing Technology, 60(1-4), 373-396. http://dx.doi.org/10.1007/s00170-011-3606-x.

Wallenius, J., Dyer, J. S., Fishburn, P. C., Steuer, R. E., Zionts, S., \& Deb, K. (2008). Multiple criteria decision making, multiattribute utility theory: recent accomplishments and what lies ahead. Management Science, 54(7), 1336-1349. http://dx.doi.org/10.1287/ mnsc. 1070.0838 .

Web of Science. (2018). Supply chain management and professional. Retrieved in 2018, August 15, from http://apps.webofknowledge.com

Wouters, M. (2009). A developmental approach to performance measures: results from a longitudinal case study. European Management Journal, 27(1), 64-78. http://dx.doi.org/10.1016/j.emj.2008.06.006.

Wu, S. J., Melnyk, S. A., \& Swink, M. (2012). An empirical investigation of the combinatorial nature of operational practices and operational capabilities: compensatory or additive? International Journal of Operations \& Production Management, 32(2), 121-155. http://dx.doi.org/10.1108/01443571211208605.

Xu, Z., Cheang, B., Lim, A., \& Wen, Q. (2011). Evaluating OR/MS journals via PageRank. Interfaces, 41(4), 375-388. http://dx.doi. org/10.1287/inte.1110.0557. 